\title{
Application of Validated TLC-Densitometric Method for Determination of Estradiol Valerate in Tablets
}

\author{
Stefka A. Ivanova ${ }^{1}$, Dobrina D. Tsvetkova ${ }^{2 *}$, Danka P. Obreshkova ${ }^{1}$
}

${ }^{1}$ Department of Chemistry and Biochemistry, Faculty of Pharmacy, Medical University Pleven, Kliment Ohridski Str. 1, 5800 Pleven, Bulgaria

${ }^{2}$ Department of Pharmaceutical Chemistry, Faculty of Pharmacy, Medical University-Sofia, Dunav Str. 2, Sofia 1000, Bulgaria

DOI: $10.36347 /$ sajp.2020.v09i02.004

| Received: 02.02.2020 | Accepted: 10.02.2020 | Published: 14.02.2020

*Corresponding author: Dobrina Doncheva Tsvetkova

\section{Abstract}

The aim of current study was the application of validated TLC-densitometric method for quality control of pharmaceutical dosage products, containing steroid component Estradiol valerate. The used materials were: Climonorm tabl. CN1 (Estradiol valerate $2 \mathrm{mg}$ ); Climonorm tabl. CN2 (Estradiol valerate $2 \mathrm{mg} /$ Levonogestrel 0.15 $\mathrm{mg}$ ); Climen tabl. CM1 (Estradiol valerate $2 \mathrm{mg}$ ); Climen tabl. CM2 tabl. (Estradiol valerate $2 \mathrm{mg} /$ Ciproterone acetate $1 \mathrm{mg}$ ). Thin layer chromatographic-densitometric method was applied. The used instrumentation was densitometer VILBER LOURMAT CN-15 LC. Chromatographic system used was: stationary phase: Silicagel $\mathrm{G}_{60} \mathrm{~F}_{254}$ glass plates; mobile phase: chloroform: acetone $=90: 10 \mathrm{v} / \mathrm{v}$, migration distance of mobile phase: $120 \mathrm{~mm}$, detection at $\lambda=254$ $\mathrm{nm}$. The amount of Estradiol valerate in Climonorm tabl. and Climen tabl. was determined by method of calibration curve by using of regression equation: $\mathrm{y}=28874286 \mathrm{x}+14290$ in concentration range: $5.10^{-4} \mathrm{~g} / \mathrm{ml} \div 3.10^{-3} \mathrm{~g} / \mathrm{ml}$. LOD $=3.15 .10^{-4} \mathrm{~g} / \mathrm{ml} ;$ LOQ $=9.54 \cdot 10^{-3} \mathrm{~g} / \mathrm{ml}$. Analytical parameter precision (repeatability) is presented by standard deviation (SD) and related standard deviation (RSD) and is proved by the fact that all of the experimental results for

the content of Estradiol valerate correspond to the respective confidence interval: $\bar{X} \pm \mathrm{t} . \mathrm{S} X$ : Climonorm CN1 tabl.: $1.78 \mathrm{mg} \div 2.1 \mathrm{mg}$; SD = 0.09; Climonorm CN2 tabl.: $2 \mathrm{mg} \div 2.16 \mathrm{mg}$; SD $=0.08$; Climen CM1 tabl.: $1.81 \mathrm{mg} \div 2.13$ $\mathrm{mg} ; \mathrm{SD}=0.09$; Climen CM2 tabl.: $1.77 \mathrm{mg} \div 2.09 \mathrm{mg}$; SD $=0.09$. The proposed TLC-densitometric method is appropriate for identification and determination of Estradiol valerate in commercially available tablets.

Keywords: Estradiol valetate, TLC, densitometry, tablets, determination.

Copyright @ 2020: This is an open-access article distributed under the terms of the Creative Commons Attribution license which permits unrestricted use, distribution, and reproduction in any medium for non-commercial use (NonCommercial, or CC-BY-NC) provided the original author and source are credited.

\section{INTRODUCTION}

Osteoporosis is designated as the third socially significant disease in the world and is caused by the reduced levels of estrogen [1], which lead to increasing of the expression of Interleukin 1, Interleukin 6 and tumor necrosis factor $\alpha(\mathrm{TNF}-\alpha)$ [2]. Interleukin 6 enhances the viability of the osteoclasts, inhibits apoptosis and increases the duration of their life cycle, as a result of which occurs osteoporosis [3]. Receptor activator of nuclear factor (RANK) $\mathrm{kB}$ and reactive oxygen species stimulate the expression of TNF- $\alpha$ in osteoclast precursor cells, which leads to increased bone resorption [4]. Phytoestrogens are polyphenolic plant metabolites [5], have estrogene activity and show a higher affinity for $\beta$-estrogen receptors due to the structural similarity with $17 \beta$-Estradiol [6].

In therapy of osteoporosis the combined drugs from different classes show additive effects in fracture treatment [7, 8]. The use of bisphosphonates with hormones has additive effects on decreasing of bone resorption markers [9]. Estrogens (0.625 mg/day) in combination with Bazedoxifene $(20 \mathrm{mg} /$ day $)$ enhance bone density [10]. Combination Estradiol/Progestin reduces the risk of fractures [11].

Estradiol valerate is available on market in drug combinations: Estradiol valerate/Cyproterone acetate [12]; Estradiol valerate/Dienogest for treatment of primary dysmenorrhea [13] and as oral contraceptive [14-17].

For analysis of drugs have been reported different analytical instrumental methods:

1. RP-HPLC with UV-detection: for drugs in dosage preparations: Asenapine at $\lambda=220 \mathrm{~nm}$ [18]; Zolpidem tartrate at $\lambda=300 \mathrm{~nm}$ [19]; simultaneous determination of Metformin and Benfotiamine at $\lambda=230 \mathrm{~nm}$ [20]. 
2. GC-MS: for analysis of herbal extracts [21].

3. HPTLC: for Bosentan in tablets [22].

4. UV-spectrophotometry: for determination of drugs in pharmaceutical dosage formulations: Stavudine at $\lambda=270 \mathrm{~nm}$ [23]; simultaneous estimation of Artesunate $\lambda=242 \mathrm{~nm}$ and Mefloquine hydrochloride $\lambda=256 \mathrm{~nm}$ [24].

5. visible apectrophotometry: Lamivudine after derivatization reaction with methyl red reagent at $\lambda=570 \mathrm{~nm}[25]$.

For quantification of Estradiol valerate in tablets is described first order derivative UVspectrophotometry at $\lambda=270 \mathrm{~nm}$ [26] and HPLC - RP with UV-detection at $\lambda=220 \mathrm{~nm}$ using $\mu$ Bondapak Phenyl column ( $3.9 \mathrm{~mm}$ x $30 \mathrm{~mm}$ x $5 \mu \mathrm{m})$, mobile phase: acetonitrile: water $=80: 20 \mathrm{v} / \mathrm{v}$ and flow rate: 0.8 $\mathrm{ml} / \mathrm{min}$ [27].

For determination of Estradiol valerate in drug combinations with other components in tablets are developed the following methods:

- First derivative UV-spectrophotometry: 1) at $283.1 \mathrm{~nm}$ for Estradiol valerate and $269.9 \mathrm{~nm}$ and $297.7 \mathrm{~nm}$ for Cyproterone acetate [28].

- Gas chromatography-mass spectrometry: Estradiol valerate and Medroxyprogesterone acetate [29].

- HPLC with UV-detection: 1) Estradiol valerate/Dienogest: stationary phase: $\mathrm{ACE} \mathrm{C}_{8}$, mobile phase: ammonium nitrate: acetonitrile $=30: 70 \mathrm{v} / \mathrm{v}$, flow rate: $2 \mathrm{ml} / \mathrm{min}$., $\lambda=280 \mathrm{~nm}$, internal standard: Cyproterone acetate [30].

In our previous works have been applied TLCdensitometry [31] and HPLC-HILIC method for determination of Estradiol hemhydrate [32]. The aim of current study was the application of the validated TLCdensitometric method for identification and determination of Estradiol valerate in dosage forms.

\section{MATERIALS AND METHODS}

\section{Drug products - tablets}

- Climonorm CN1 tabl. (WEKSBH, Bayer, Germany): Estradiol valerate $2 \mathrm{mg}$

- Climonorm CN2 tabl. (WEKSBH, Bayer, Germany): Estradiol valerate 2 $\mathrm{mg} /$ Levonogestrel $0.15 \mathrm{mg}$

- $\quad$ Climen CM1 tabl. (344418, Bayer, Germany): Estradiol valerate $2 \mathrm{mg}$

- Climen CM2 tabl. (344418, Bayer, Germany): Estradiol valerate $2 \mathrm{mg} /$ Ciproterone acetate 1 $\mathrm{mg}$

Reference standard: Estradiol valerate with chemical purity.

Reagents with analytical grade quality: chloroform (Sigma Aldrich, N: SZBD 074SV UN 1888); acetone
(Sigma Aldrich, N: SZBC 1861 SV); $99.98 \%$ ethanol (Sigma Aldrich, N: SZBD 0500V UN 1170), distilled water.

\section{METHODS: TLC-Densitometry \\ Instrumentation}

Densitometer VILBER LOURMAT CN-15 LC

Serial: 16263; sample applicator $10 \mu$ micropipette (Hamilton, Bonaduz, Switzerland, N:18005701); TLC glass chamber $(22 \mathrm{~cm} \times 12 \mathrm{~cm} \times 22 \mathrm{~cm})$; stationary phase: TLC glass plates Silicagel $\mathrm{G}_{60} \mathrm{~F}_{254}, 20 \mathrm{~cm}$ x 20 cm (Sigma Aldrich, N: 2364681) were used.

\section{Chromatographic Conditions}

Stationary phase: TLC glass plates precoated with Silicagel $\mathrm{G}_{60} \mathrm{~F}_{254}$, mobile phase: chloroform: acetone $=90: 10 \mathrm{v} / \mathrm{v}$, migration distance of mobile phase: $120 \mathrm{~mm}$, detection at $\lambda=254 \mathrm{~nm}$.

Preparation of test solutions from dosage formulations (tablets), containing Estradiol valerate for investigation of analytical parameter precision (repeatability)

Separately from every drug formulation 20 tablets were weighed accurately. From homogenous powdered tablets from every drug preparation accuratelly were weighed 6 samples, containing an amount equivalent respectively to $20 \mathrm{mg}$ Estradiol valerate. Every sample was transferred separately to a $10.0 \mathrm{ml}$ volumetric flask and was diluted with $99.98 \%$ ethanol. The solutions were filtered through a blue band filter and were analyzed by densitometric method described.

\section{Chromatographic Procedure}

Chromatographic analysis was achieved by using glass TLC plates. From every solution separatelly were spotted aliquot parts of $10 \mu \mathrm{l}$ onto glass plates Silicagel $\mathrm{G}_{60} \mathrm{~F}_{254}$, keeping $10 \mathrm{~mm}$ distance between bands. The plate was developed about at $25^{\circ} \mathrm{C} \pm 1{ }^{\circ} \mathrm{C}$ in ascending vertical manner in glass chromatographic chamber, previously presaturated for $1 \mathrm{~h}$ with mobile phase: chloroform: acetone $=90: 10 \mathrm{v} / \mathrm{v}$. The migration distance of the mobile phase in all experiments was 12 $\mathrm{mm}$. The developed plates were dried on air. Densitometric scanning was performed on scanner VILBER LOURMAT CN-15 LC, operated in the absorbance mode at $\lambda=254 \mathrm{~nm}$.

\section{RESULTS AND DISCUSSION}

In recent work the validated TLCdensitometric method was appliyed for identification and determination of Estradiol valerate in dosage pharmaceutical formulations - tablets. The obtained by TLC-densitometric method chromatograms of tablets are illustrated on Figure-1. for Climonorm CN1 tabl. and Climonorm CN2 tabl. and on Figure-2. for Climen CM1 tabl. and Climen CM2 tabl. 


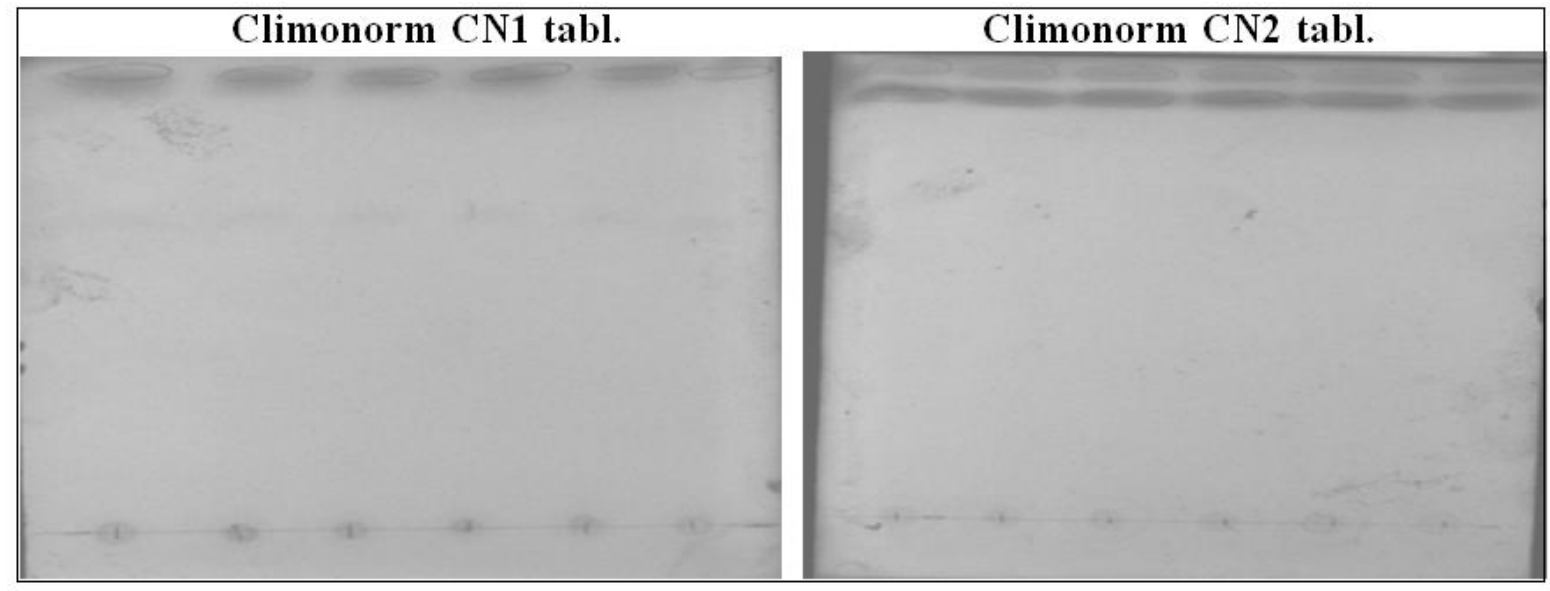

Fig-1: Chromatograms of Estradol valerate in Climonorm CN1 tabl. and Climonorm CN2 tabl.

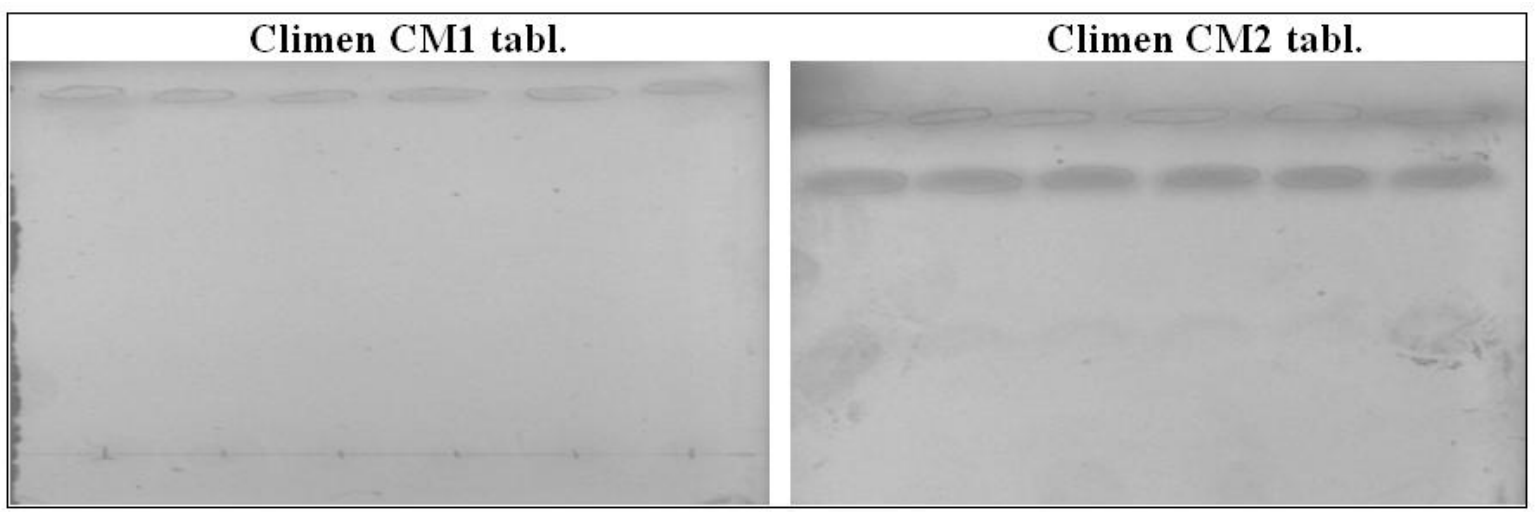

Fig-2: Chromatograms of Estradol valerate in Climen CM1 tabl. and Climen CM2 tabl.

On Table-1 are presented the data for the values of Rf, radius $\mathrm{r}[\mathrm{cm}]$ and area of the spots $\mathrm{S}\left[\mathrm{cm}^{2}\right]$ for Estradiol valerate in Climonorm tabl. and Climen tabl.

Table-1: Results for Rf and $\mathbf{r}[\mathrm{cm}]$ and $S$ [ $\left.\mathrm{cm}^{2}\right]$ for Estradol valerate in Climonorm tabl. and Climen tabl

\begin{tabular}{|c|c|c|c|c|c|c|}
\hline \multirow[t]{2}{*}{ N: } & \multicolumn{3}{|c|}{ Climonorm CN1 tabl. } & \multicolumn{3}{|c|}{ Climonorm CN2 tabl. } \\
\hline & Rf & $\mathbf{r}[\mathbf{c m}]$ & $\mathrm{S}\left[\mathbf{c m}^{2}\right]$ & $\mathbf{R f}$ & $\mathbf{r}[\mathbf{c m}]$ & $\mathrm{S}\left[\mathbf{c m}^{2}\right]$ \\
\hline 1. & 1.08 & 0.14 & 0.0615 & 1.09 & 0.15 & 0.0707 \\
\hline 2. & 1.09 & 0.15 & 0.0707 & 1.1 & 0.16 & 0.0804 \\
\hline 3. & 1.09 & 0.15 & 0.0707 & 1.08 & 0.14 & 0.0615 \\
\hline 4. & 1.08 & 0.14 & 0.0615 & 1.09 & 0.15 & 0.0707 \\
\hline 5. & 1.08 & 0.14 & 0.0615 & 1.1 & 0.16 & 0.0804 \\
\hline 6. & 1.1 & 0.16 & 0.0804 & 1.09 & 0.15 & 0.0707 \\
\hline \multirow[t]{2}{*}{$\mathbf{N}:$} & \multicolumn{3}{|c|}{ Climen CM1 tabl. } & \multicolumn{3}{|c|}{ Climen CM2 tabl. } \\
\hline & Rf & $\mathbf{r}[\mathbf{c m}]$ & $\mathrm{S}\left[\mathrm{cm}^{2}\right]$ & $\mathbf{R f}$ & $\mathbf{r}[\mathbf{c m}]$ & $\mathrm{S}\left[\mathrm{cm}^{2}\right]$ \\
\hline 1. & 1.1 & 0.16 & 0.0804 & 1.09 & 0.15 & 0.0707 \\
\hline 2. & 1.09 & 0.15 & 0.0707 & 1.09 & 0.15 & 0.0707 \\
\hline 3. & 1.08 & 0.14 & 0.0615 & 1.08 & 0.14 & 0.0615 \\
\hline 4. & 1.09 & 0.15 & 0.0707 & 1.09 & 0.15 & 0.0707 \\
\hline 5. & 1.1 & 0.16 & 0.0804 & 1.08 & 0.14 & 0.0615 \\
\hline 6. & 1.09 & 0.15 & 0.0707 & 1.1 & 0.16 & 0.0804 \\
\hline
\end{tabular}

On Table-2 are summarized the results for spot area (A) and Chauvenet's criterion for spot area (UA) and quantity (UC) of Estradiol valerate in Climonorm tabl. and Climen tabl. 
Table-2: Spot area and Chauvenet's criterion for the spot area (UA) and quantity (UC) of Estradiol valerate in Climonorm tabl. and Climen tabl

\begin{tabular}{|c|c|c|c|c|c|c|}
\hline \multirow[t]{2}{*}{$\mathbf{N}:$} & \multicolumn{3}{|c|}{ Climonorm CN1 tabl. } & \multicolumn{3}{|c|}{ Climonorm CN2 tabl. } \\
\hline & $\mathbf{A}$ & UA & $\mathbf{U C}$ & A & UA & $\mathbf{U C}$ \\
\hline 1. & 70200 & 0.35 & 0.33 & 72500 & 0.62 & 0.63 \\
\hline 2. & 71800 & 0.27 & 0.33 & 77000 & 1.28 & 1.38 \\
\hline 3. & 72400 & 0.51 & 0.56 & 70700 & 1.38 & 1.38 \\
\hline 4. & 68100 & 1.18 & 1.11 & 73100 & 0.37 & 0.38 \\
\hline 5. & 69000 & 0.82 & 0.78 & 76200 & 0.95 & 1.0 \\
\hline 6. & 75100 & 1.57 & 1.56 & 74300 & 0.14 & 0.25 \\
\hline $\bar{X}$ & 71100 & & & 73967 & & \\
\hline SD & 2546 & & & 2361 & & \\
\hline RSD & 3.58 & & & 3.19 & & \\
\hline \multirow[t]{2}{*}{$\mathbf{N}:$} & \multicolumn{3}{|c|}{ Climen CM1 tabl. } & \multicolumn{3}{|c|}{ Climen CM2 tabl. } \\
\hline & $\mathbf{A}$ & $\mathbf{U A}$ & $\mathbf{U C}$ & $\mathbf{A}$ & $\mathbf{U A}$ & $\mathbf{U C}$ \\
\hline 1. & 72500 & 0.25 & 0.22 & 69100 & 0.61 & 0.56 \\
\hline 2. & 71400 & 0.19 & 0.11 & 71200 & 0.17 & 0.22 \\
\hline 3. & 70000 & 0.74 & 0.67 & 68800 & 0.72 & 0.67 \\
\hline 4. & 72600 & 0.29 & 0.33 & 72400 & 0.62 & 0.67 \\
\hline 5. & 76000 & 1.64 & 1.66 & 67900 & 1.06 & 1.11 \\
\hline 6. & 68700 & 1.26 & 1.22 & 75000 & 1.6 & 1.66 \\
\hline $\bar{X}$ & 71867 & & & 70733 & & \\
\hline SD & 2520 & & & 2670 & & \\
\hline RSD & 3.51 & & & 3.77 & & \\
\hline
\end{tabular}

The amount of Estradiol valerate in analysed tablets was determined by method of a calibration curve and results are included in Table-3.

Table-3: Content of Estradiol valerate in Climonorm tabl. and Climen tabl

\begin{tabular}{|c|c|c|c|c|}
\hline \multirow[t]{2}{*}{$\mathbf{N}:$} & \multicolumn{2}{|c|}{ Climonorm tabl. } & \multicolumn{2}{|c|}{ Climen tabl. } \\
\hline & [CN1] & [CN2] & [CM1] & [CM2] \\
\hline 1. & 1.91 & 1.99 & 1.99 & 1.88 \\
\hline 2. & 1.97 & 2.15 & 1.96 & 1.95 \\
\hline 3. & 1.99 & 1.93 & 1.91 & 1.87 \\
\hline 4. & 1.84 & 2.01 & 2.00 & 1.99 \\
\hline 5. & 1.87 & 2.12 & 2.12 & 1.83 \\
\hline 6. & 2.08 & 2.06 & 1.86 & 2.08 \\
\hline $\bar{X} \pm \mathrm{SD}$ & $1.94 \pm 0.09$ & $\begin{array}{l}2.04 \pm \\
0.08\end{array}$ & $\begin{array}{l}1.97 \pm \\
0.09\end{array}$ & $\begin{array}{l}1.93 \pm \\
0.09\end{array}$ \\
\hline SD & 0.09 & 0.08 & 0.09 & 0.09 \\
\hline RSD [\%] & 4.64 & 3.92 & 4.57 & 4.66 \\
\hline $\mathrm{s} \bar{X}$ & 0.04 & 0.03 & 0.04 & 0.04 \\
\hline $\mathrm{P}[\%]$ & 99.0 & 99.0 & 99.0 & 99.0 \\
\hline $\mathrm{t}$ & 4.03 & 4.03 & 4.03 & 4.03 \\
\hline t.S $\bar{X}$ & 0.16 & 0.12 & 0.16 & 0.16 \\
\hline $\begin{array}{l}\bar{X}-\mathrm{t} . \mathrm{S} \bar{X} \div \\
\bar{X}+\mathrm{t} . \mathrm{S} \bar{X}\end{array}$ & $\begin{array}{l}1.78 \div \\
2.1\end{array}$ & $\begin{array}{l}1.92 \div \\
2.16\end{array}$ & $\begin{array}{l}1.81 \div \\
2.13\end{array}$ & $\begin{array}{l}1.77 \div \\
2.09\end{array}$ \\
\hline $\mathrm{E}[\%]$ & 2.06 & 1.47 & 2.03 & 2.07 \\
\hline
\end{tabular}

\section{DISCUSSION}

In our previous work [33] a TLC-densitometric method for Estradiol valerate was validated in accordance with International Conference on
Harmonization guidelines for validation of analytical procedures for analytical parameters: limearity, limit of detection (LOD), limit of quantitation (LOQ), accuracy and precission (repeatability) [34, 35]. 
Placebo solution, containing as supplement starch, without the active substance Estradiol valerate was prepared. The selectivity of the applied method was confirmed by the fact that on chromatogram with placebo preparation did not exist spot with Rf, corresponding to $\mathrm{Rf}$ of Estradiol valerate in reference standard solution. This fact confirms that there was no interference from the commonly present in tablets excipient starch [33].

The calibration curve was obtained by using the data for 6 different concentrations of standard solutions of Estradiol valerate and was generated by plotting the sample concentration versus the mean peak area. Linear regression analysis was performed. Linearity accordance between the concentration and spot area in range: $5.10^{-4} \mathrm{~g} / \mathrm{ml} \div 3.10^{-3} \mathrm{~g} / \mathrm{ml}$ was proved by the regression equation: $y=28874286$. $x+14290$ (y - peak area, $x$ - concentration of analyte). The least squares regression yielded a correlation coefficient $\mathrm{R}=$ 0.99. Limit of detection and limit of quantitation were determined by using of the standard deviation of the response and the slope of the regression equation for the calibration curve. The limit of detection, defined the concentration giving a signal with signal to noise ratio of 3 , is LOD $=3.15 \cdot 10^{-4} \mathrm{~g} / \mathrm{ml}$. The limit of quantitation, defined the concentration giving a signal with signal to noise ratio of 10 , is $\mathrm{LOQ}=9.54 \cdot 10^{-3} \mathrm{~g} / \mathrm{ml}$ [33].

The content of drug in model mixtures was determined by method of calibration curve using the regression equation. For the estimation of analytical parameter accuracy the degree of recovery is presented in $\mathrm{R}[\%] \pm \mathrm{RSD}[\%]$ and suit respective confidence interval: R [1.5 mg]: $95.92 \% \div 103.98 \%$; R [2 mg]: $93.35 \% \div 108.89 \%$; R [2.5 mg]: $95.37 \% \div 103.77 \%$ [33].

For the estimation of an analytical parameter precision (repeatability) was used the uncertainty of the result, which is determined by: standard deviation (SD), relative standard deviation (RSD) and confidence interval. SD was calculated sample standard deviation (SD), by the applying of the Bessel's correction, in which the denominator $\mathrm{N}-1$ (degrees of freedom) is used instead of $\mathrm{N}$ and in this case $(\mathrm{S})^{2}$ is an unbiased estimator for $(\mathrm{SD})^{2}$. All data for the obtained quantity correspond to the confidence interval: $1.88 \mathrm{mg} \div 2.17$ $\mathrm{mg}$ [33].

In recent study the validated TLCdensitometric method was applied for identification and determination of Estradiol valerte in dosage forms tablets: Climonorm CN1 tabl. and Climen CM2 tabl.: Estradiol valerate $2 \mathrm{mg}$; Climonorm CN2 tabl.: Estradiol valerate $2 \mathrm{mg} /$ Levonogestrel $0.15 \mathrm{mg}$; Climen CM2 tabl. Estradiol valerate $2 \mathrm{mg} /$ Ciproterone acetate $1 \mathrm{mg}$.

Chemical structures of Estradiol valerate, Levonogestrel and Ciproterone acetate are illustrated on Figure-3.

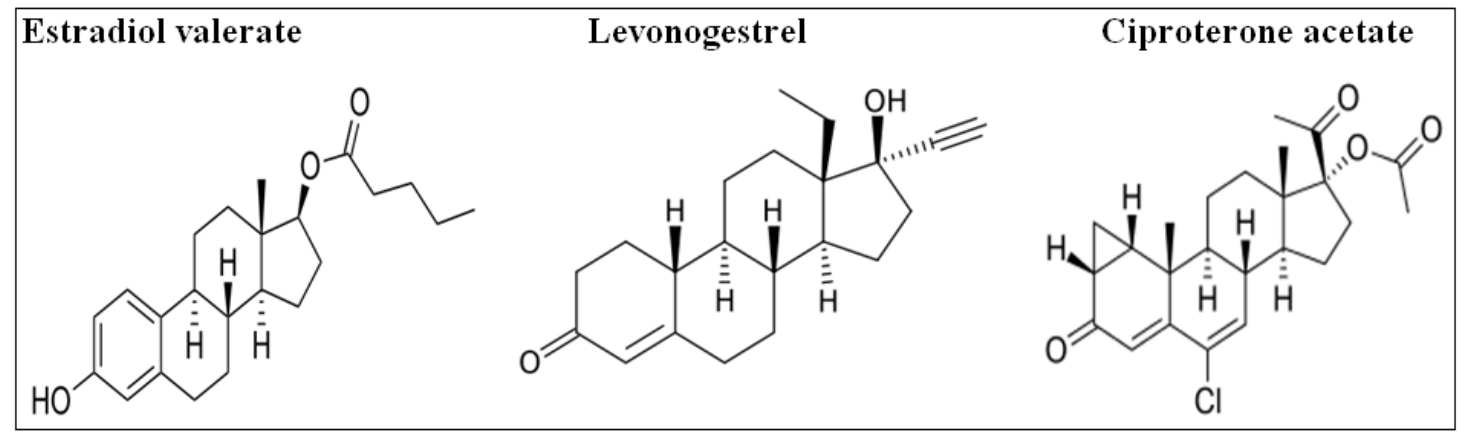

Fig-3: Chemical structures of Estradiol valerate, Levonogestrel and Ciproterone acetate

The amount of Estradiol valerate in Climonorm tabl. and Climen tabl (Table-3) was determined by a calibration curve using the regression equation: $\mathrm{y}=28874286 . \mathrm{x}+14290$.

From Table-2 it is obvious that for all of the analysed tablets the calculated Chauvet's criterion for the area of the spots (UA) and for the quantities (UC) of Estradiol valerate are lower than the maximum value of the criterion ( $\operatorname{Umax}=1.73 ; \mathrm{N}=6)$, which proves that the results suit to the requirements of the criterion for the analysis of 6 separete samples from Climonorm tabl. and Climen tabl. All of the experimental results for the content of Estradiol valerate correspond to the respective confidence interval: Climonorm $\mathrm{CN} 1$ tabl. $(1.78 \mathrm{mg} \div 2.1 \mathrm{mg}, \mathrm{SD}=0.09)$; Climonorm CN2 tabl. $(2 \mathrm{mg} \div 2.16 \mathrm{mg}, \mathrm{SD}=0.08)$; Climen CM1 tabl. $(1.81$ $\mathrm{mg} \div 2.13 \mathrm{mg}, \mathrm{SD}=0.09)$; Climen CM2 tabl. $(1.77 \mathrm{mg}$ $\div 2.09 \mathrm{mg}, \mathrm{SD}=0.09$ ).

\section{CONCLUSIONS}

Estradiol valerate is available on market in drug combinations with: Ciproterone acetate, Dienogest, Medroxyprogesterone acetate, Levonogestrel. The validated TLC-densitometric method was appliyed for the identification and determination of Estradiol valerate in tablets. The analytical parameter repeatability for the content of 
drug in tablets is characterized with SD and RSD. The results showed that all of the experimental results for the content correspond to the respective confidence interval. The proposed validated TLC-densitometric method is appropriate for quality control of Estradiol valerate in commercially available tablets.

\section{REFERENSES}

1. Rachner TD, Khosla S, Hofbauer LC. Osteoporosis: now and the future. Lancet, 2011, 377(9773): 1276-1287.

2. Krassas GE, Papadopoulou P. Oestrogen action on bone cells. J Musculoskelet Neuronal Interact, 2001;2(2):143-151.

3. Mysliwiec J, Adamczyk M, Nikolajuk A, Gorska M. Interleukin-6 and its considerable role in the pathogenesis of thyrotoxicosis-related disturbances of bone turnover in postmenopausal women. Endokrynol Pol, 2011;62(4):299-302.

4. Kyung TW, Lee JE, Shin HH, Choi HS. Rutin inhibits osteoclast formation by decreasing reactive oxygen species and $\mathrm{TNF}-\alpha$ by inhibiting activation of NF-kB. Exp Mol Med, 2008;40(1):52-58.

5. Sacco SM, Horcajada MN, Offord E. Phytonutrients for bone health during ageing. Br J Clin Pharmacol, 2013;75(3):697-707.

6. Habauzit V, Horcajada MN. Phenolic phytochemicals and bone. Phytochem Rev, 2008;7(2):313-344.

7. Lim SY, Bolster MB. Current approaches to osteoporosis treatment. Curr Opin Rheumatol, 2015;27(3):216-224.

8. Ivanova St, Tsvetkova D, Danchev N. Ethiology of osteoporosis and therapeutic strategies. Sci Pharmacol, 2017;2(1) 25-32.

9. Eviö S, Tiitinen A, Laitinen K, Ylikorkala O, Välimäki MJ. Effects of Alendronate and hormone replacement therapy, alone and in combination, on bone mass and markers of bone turnover in elderly women with osteoporosis. J Clin Endocrinol Metab, 2004;89(2):626-631.

10. Lobo RA, Pinkerton JV, Gass ML, Dorin MH, Ronkin S, Pickar JH, Constantine G. Evaluation of Bazedoxifene/conjugated estrogens for the treatment of menopausal symptoms and effects on metabolic parameters and overall safety profile. Fertil Steril, 2009;92(3):1025-1038.

11. Cauley JA, Robbins J, Chen Z, Cummings SR, Jackson RD, LaCroix AZ, LeBoff M, Lewis CE, McGowan J, Neuner J, Pettinger M, Stefanick ML, Wactawski-Wende J, Watts NB. Effects of estrogen plus progestin on risk of fracture and bone mineral density: the Women's Health Initiative randomised trial. JAMA, 2003;290(13):1729-1738.

12. Mares P, Dauzat M, Abramovici Y, Deklunder G, Body G, Crepin G, Denis A, Favier M. Effects of a sequential combination of Estradiol valerate and Cyproterone acetate on the functional properties of the arterial wall in menopausal women. Gynecol Obstet Fertil, 2000;28(7-8):509517.

13. Petraglia F, Parke S, Serrani M, Mellinger U, Römer T. Estradiol valerate plus Dienogest versus Ethinylestradiol plus Levonorgestrel for the treatment of primary dysmenorrheal. Int J Gynecol Obstetr, 2014;125(3):270-274.

14. Borgelt LM, Martell CW. Estradiol valerate/Dienogest: a novel combined oral contraceptive. Clin Ther, 2012;34(1):37-55.

15. Macìas G, Merki-Feld GS, Merki-Feld GS, Parke S, Mellinger U, Serrani M. Effects of a combined oral contraceptive containing Estradiol valerate/Dienogest on hormone withdrawalassociated symptoms: results from the multicentre, randomised, double-blind, active-controlled HARMONY II study. J Obstet Gynaecol, 2013;33(6):591-596.

16. Palacios S, Wildt L, Parke S, Machlitt A, Römer T, Bitzer J. Efficacy and safety of a novel oral contraceptive based on Estradiol (Estradiol valerate/Dienogest): A phase III trial. Eur J Obstet Gynaecol Reprod Biol, 2010;149(1):57-62.

17. Zeun S, Lu M, Uddin A, Zeiler B, Morrison D, Blode H. Pharmacokinetics of an oral contraceptive containing Estradiol valerate and Dienogest. Eur J Contracept Reprod Health Care, 2009;14(3):221-232.

18. Shyamala YV, Sharma JVC, Harikrishna E, Jadav P. Validated RP-HPLC method for estimation of Asenapine in bulk and tablet dosage form Sch Acad J Pharm, 2018;7(5):194-197.

19. Kiran M, Ushasri S, Nissankarao S. Development and validation of new RP-HPLC method for the determination of Zolpidem tartrate in pure and pharmaceutical formulations. Sch Acad J Pharm, 2013;2(5):360-364

20. Tandrima M, Lakshmi S, Yasodha A. Development and validation of a RP-HPLC-PDA method for the simultaneous determination of Metformin and Benfotiamine in active pharmaceutical ingredient and pharmaceutical dosage form. Sch Acad J Pharm, 2018;7(7):341347.

21. Sivakamasundari, Ravishankar, Mariajancyrani J, Chandramohan. GC-MS analysis of chloroform extract of Solanum Nigrum Leaf. Sch Acad J Pharm, 2013;2(3):268-273.

22. Suganthi A, Sai LCH, Vinod S, Ravi TK. Development and validation of UV spectroscopic and HPTLC methods for the determination of Bosentan from tablet dosage form. Sch Acad J Pharm, 2014;3(2):123-127.

23. Khadeer ZS, Srinivasulu Y, Pushpa LE. Development and validation of new spectrophotometric method for the estimation of Stavudine in bulk and pharmaceutical dosage form. Sch Acad J Pharm, 2013;2(4):319-322. 
24. Sapakal AD, Wadkar KA, Mohite SK, Magdum CS. Development and validation of UV-method for simultaneous estimation of Artesunate and Mefloquine hydrochloride in bulk and marketed formulation. Sch. Acad. J. Pharm, 2013;2(4):293297.

25. Sreenivasulu Y, Khadeer ZS, Pushpa LE. Development and validation of visible spectrophotometric method for the estimation of Lamivudine in bulk and pharmaceutical dosage form. Sch. Acad. J. Pharm, 2013;2(4):323-326.

26. Mendez ASL. Deconto L, Garcia DC. UVderivative spectrophotometric method for determination of Estradiol valerate in tablets. Quim Nova, 2010;33(4):981-983.

27. Madhu M, Satyadev TNVSS, Hephzibah G, Reddy TV. Validated RP-HPLC method for the determination of Estradiol valerate in bulk and pharmaceutical formulations. Der Pharmacia Lettre, 2016;8(4):50-61.

28. Yucesoy C, Erol S. Derivative and difference spectrophotometric determination of Cyproterone acetate and Estradiol valerate in formulations. Fabad J Pharm Sci, 2000;25(3):85-90.

29. Yilmaz B. Simultaneous determination of Estradiol valerate and Medroxyprogesterone acetate in a tablet formulation by gas chromatography-mass spectrometry. Anal Sci, 2010;26(3):391-393.

30. Cağlayan MG, Palabiyik IM, Onur F. Development and validation of spectrophotometric and high-performance column liquid chromatographic methods for the simultaneous determination of Dienogest and Estradiol valerate in pharmaceutical preparations. J AOAC Int, 2010;93(3):862-868.

31. Tsvetkova D, Obreshkova D, Ivanova St, Hadjieva B. Application of TLC-densitometry for analysis of Estradiol hemhydrate in dosage forms. Indian $\mathrm{J}$ Pharm Educ Res, 2016;50(3):482-488.

32. Tsvetkova DD, Ivanova SA, Saso L, Obreshkova D, Dimitrov M. Estimation of linearity and precision of HPLC-HILIC method for analysis of Estradiol hemihydrate. Bulg Chem Commum, 2017; 49(2):384-389.

33. Ivanova St, Tsvetkova D. Validation of TLCdensitometric method for quality control of Estradiol valerate in drug combinations. Bulg Chem Commun, 2016;48(3):456-460.

34. International Conference on Harmonization Guidelines. Validation of analytical procedures: text and methodology Q2 (R1): FDA Fed Regist. 1995; 60(1): 11260.

35. Madhav NVS, Ojha A, Singh S. Validation: a significant tool for enhancing qualities of pharmaceutical products. Sch Acad J Pharm, 2017;6(6):288-299. 